\title{
Analysis of pig derivatives for halal authentication studies
}

\begin{abstract}
Pig derivatives such as lard and pork in any food system are prohibited for consumption by Muslims and Jews. For this reason, analytical methods offering accurate and reproducible results are needed to assure the halalness, kosherness, and wholesomeness of food. This article describes some analytical techniques, namely Fourier transform infrared (FTIR) spectroscopy, chromatography-based techniques, differential scanning calorimetric (DSC), and electronic noses for detection and quantification of pig derivatives (lard, pork, gelatin) in food products.
\end{abstract}

Keyword: Food; Gelatin; Halal; Kosher; Lard; Physichochemical technique; Pig derivatives; Pork 